PontIFícIA UNIVERSIDADE CATÓLICA dO RIO DE JANEIRO

Comunidades não oficiais de marca Harley-Davidson

João Marcos Joras Ribeiro

Trabalho de Conclusão de Curso

Centro de CIÊnCIAS SOCIAIS - CCS

DEPARTAMENTO dE AdMINISTRAÇÃO

Graduação em Administração de Empresas 
João Marcos Joras Ribeiro

\section{Comunidades não oficiais de marca}

Harley-Davidson

Trabalho de Conclusão de Curso

Trabalho de Conclusão de Curso, apresentado ao programa de graduação em Administração da PUC-Rio como requisito parcial para a obtenção do título de graduação em Administração.

Orientadora: Barbara Pagliari Levy

Rio de Janeiro

dezembro de 2020. 


\section{Agradecimentos}

Primeiramente gostaria de agradecer a todos que contribuíram, disponibilizando tempo para participar da pesquisa e sempre buscando 0 enriquecimento do meu trabalho.

Agradeço a minha orientadora Barbara Pagliari Levy por aceitar conduzir o meu trabalho de pesquisa.

A minha mãe Cláudia Joras de Oliveira por ter se mobilizado, ajudando a encontrar pessoas nesse tempo de pandemia

Ao meu pai Marcos José Vieira Ribeiro que sempre me apoiou ao longo de toda a minha trajetória, emocionalmente e financeiramente.

E ao meu irmão Daniel Joras Ribeiro pelo apoio e comentários que contribuíram para o desenvolvimento do estudo. 


\section{Resumo}

Ribeiro, João Marcos Joras. Comunidades não oficiais de marca HarleyDavidson. Rio de Janeiro, 2020. 32 p. Trabalho de Conclusão de Curso Departamento de Administração. Pontifícia Universidade Católica do Rio de Janeiro.

O trabalhou buscou analisar comunidades não oficiais da empresa HarleyDavidson na cidade do Rio de Janeiro. Foi feito um estudo com comunidades monomarcas investigando suas características, entendendo a relação dos consumidores com a marca e com a coletividade e as principais motivações para entender o porquê da não adesão com a comunidade oficial que a marca promove e sim das não oficiais. Como estratégia de investigação, foram realizadas 15 entrevistas através de um roteiro semiestruturado com o método bola de neve que levou aos resultados que a comunidade oficial é inexperiente e menos focada no estilo de vida e por isso buscam comunidades com filosofias e estilos de vida mais alinhadas com a que a marca defende.

Palavras- chave

Harley-Davidson, comunidade de marca, valor da marca, moto clubes

\section{Abstract}

Ribeiro, João Marcos Joras. Unofficial brand communities Harley-Davidson. Rio de Janeiro, 2020. 32 p. Trabalho de Conclusão de Curso Departamento de Administração. Pontifícia Universidade Católica do Rio de Janeiro.

The work sought to analyze unofficial communities of the company HarleyDavidson in the city of Rio de Janeiro. A study was carried out with mono-brand communities investigating their characteristics, understanding the relationship of consumers with the brand and with the community and the main motivations to understand why non-adherence to the official community that the brand promotes, but unofficial ones. As a research strategy, 15 interviews were conducted through a semi-structured script with the snowball method, which led to the results that the official community is inexperienced and less focused on lifestyle and therefore seeks communities with more aligned philosophies and lifestyles more aligned with those advocated by the brand.

\section{Key-words}

Harley-Davidson, brand community, brand equity, motorcycle club 


\section{Sumário}

1 O tema e o problema de estudo $\quad 7$

1.1. Objetivo do estudo 9

1.2. Delimitações 10

1.3. Relevância do estudo 10

2 Referencial Teórico 11

2.1. Identidade 11

2.2. Brand Equity 12

2.2.1. Pirâmide de construção do Brand Equity 14

$\begin{array}{ll}\text { 2.3. Comunidade de marca } & 16\end{array}$

2.3.1. Comunidade de Marca da Harley-Davidson 18

$\begin{array}{ll}3 \text { Metodologia } & 19\end{array}$

3.1. Método de Pesquisa 19

3.2. Universo da pesquisa 19

3.3. Coleta e tratamento de dados 20

$\begin{array}{ll}\text { 3.4. Limitações do estudo } & 20\end{array}$

4 Análise dos Resultados $\quad 22$

4.1. A Marca Harley-Davidson 23

4.2. Comunidade de Marca Harley-Davidson - H.O.G. 25

4.3. Comunidades Não Oficiais de Marca 26

$\begin{array}{ll}5 \text { Conclusão } & 29\end{array}$

$\begin{array}{ll}\text { Referências } & 31\end{array}$

$\begin{array}{ll}\text { Anexo } & 33\end{array}$ 


\section{Lista de figuras}

Figura 1: Venda mundial de motocicleta Harley-Davidson .............................. 8

Figura 2: Pirâmide de conhecimento de marca .............................................. 13

Figura 3: Pirâmide CBBE (Keller e Machado, 2006 p.48) ............................... 14

Figura 4: Diagrama sociedade .............................................................. 18

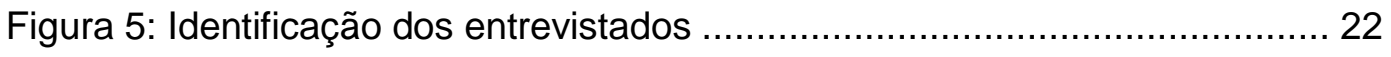

\section{Lista de Tabelas}

Tabela 1: Crescimento e decrescimento de unidades vendidas 9 


\section{0 tema e o problema de estudo}

No mundo contemporâneo, as pessoas e as empresas estão inseridas em modelos de organização e cultura, associadas a vínculos interpessoais que dão algum significado à vida (SHOUTEN; MCALEXANDER, 1995), e no processo de construção de identidades, no qual o consumo tem papel fundamental (LEÃO ET AL, 2015). A área de marketing tenta persuadir a maneira como os consumidores se comportam (HAWKINS; MOTHERSBAUGHT, 2018). Desse modo, tentar compreender o jeito como o comprador age no processo de compra é fundamental para medir o resultado da empresa, refletindo inclusive em seu valor de marca.

O valor da marca é um conceito ligado a benefícios-chave tanto para os consumidores quanto para as empresas (OLIVEIRA; LUCE, 2011) visto que, estrategicamente, marcas fortes caracterizam um componente chave de vantagem competitiva e como fonte principal de ganhos futuros para a empresa (BALADAUF ET AL, 2003). O nível mais alto de valor da marca, também chamado de brand equity, é a ressonância da marca. Ao atingir este nível, em alguns casos há também a formação de uma comunidade de marca, composta por consumidores em mais estreita ligação com a marca. Alguns exemplos de comunidade de marca observados em tempos recentes são a Apple, que incentiva seus usuários a formar grupos locais a fim de disponibilizar oportunidades de aprendizado sobre os produtos da marca e forma de aproveitá-los; a MTV, que durante sua operação criou uma comunidade por meio de atividades, eventos e novas maneiras de executar a programação, com o intuito de proporcionar uma maior conexão com o telespectador, principalmente os mais jovens; e a Harley-Davidson, a emblemática marca de motos, que tem uma estratégia de associados, criando um sentimento de comunidade com os consumidores da marca.

O presente estudo centra-se na Harley-Davidson, uma empresa americana fabricante de motocicletas fundada em 1903 e hoje considerada um ícone e uma das maiores fabricantes do mundo. Porém, em 1983, a empresa passava por uma das suas piores crises e corria o risco de fechar. Com a chance de falência, a fabricante de motos alterou a estratégia, voltando-se para uma percepção humana da marca e 
para a criação de comunidades de pessoas ao redor dela. Essa nova percepção era orientada para representar um estilo de vida dos consumidores.

A Harley-Davidson está espalhada em 22 países, sendo um deles o Brasil, com escritório em São Paulo e produção na Zona Franca de Manaus. Com um aumento de $8,9 \%$ em unidades montadas na fábrica brasileira em relação a 2018 , em 2019 a Harley-Davidson produziu 6.249 unidades e emplacou as vendas um total de 6.089 motocicletas, 5,8\% a mais que no ano anterior (TEIXEIRA, 2020). Mesmo com a recessão que o país vinha sofrendo no período ainda pré-COVID-19, a empresa se mantinha em crescimento pelo terceiro ano consecutivo.

Enquanto no Brasil a taxa de produção aumenta, no mundo as unidades vendidas vêm decaindo ao longo dos anos, tendo uma queda de 4,3\% em 2019 em relação ao ano anterior. A exceção se dá pela região denominada pela empresa por "Ásia, Pacífico", que conta com os países: Japão, Austrália, Nova Zelândia e Coréia do Sul, como demonstram a Figura 1 e a Tabela 1.

Figura 1: Venda mundial de motocicleta Harley-Davidson

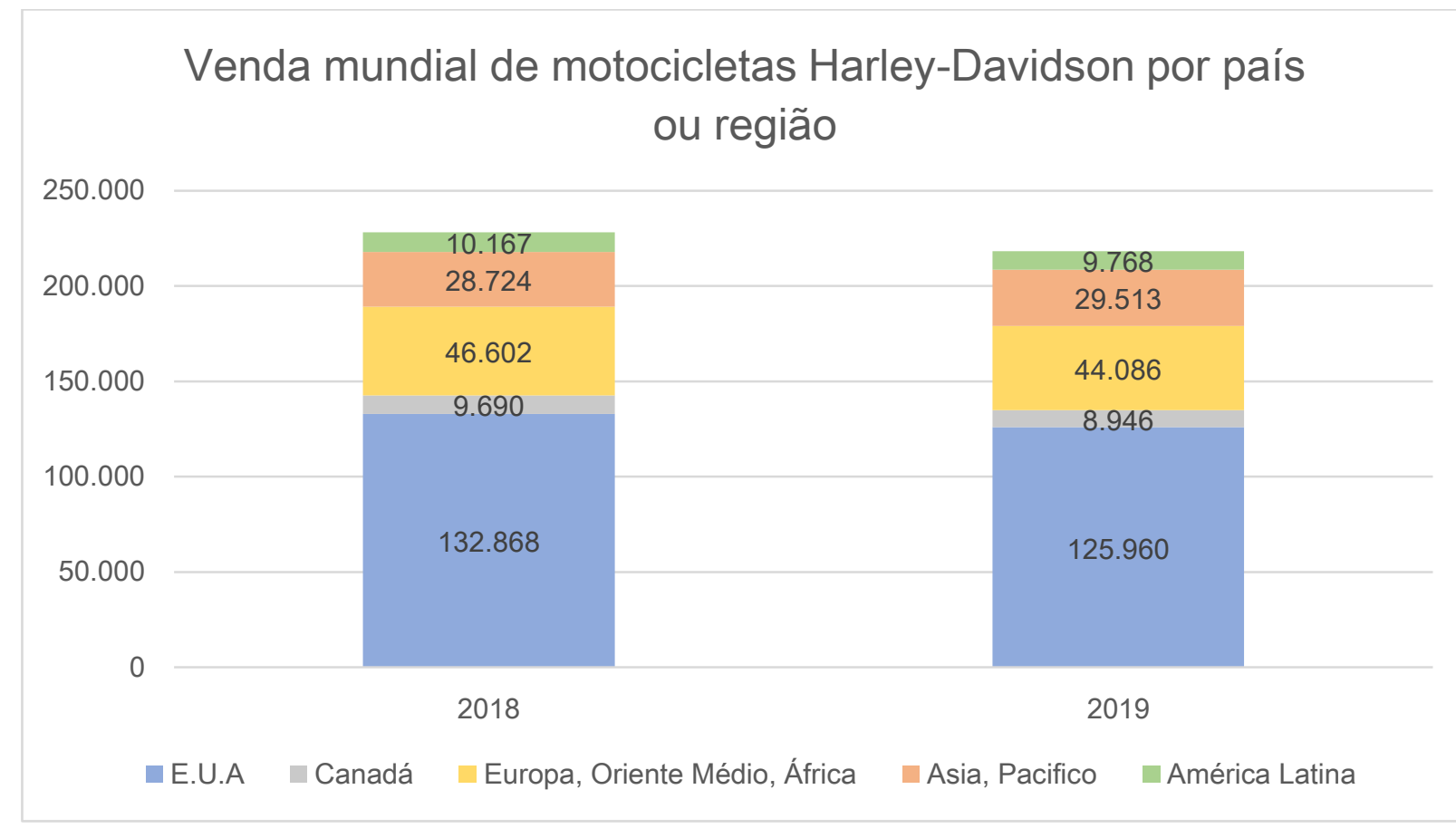

Adaptado de: http://investor.harley-davidson.com/news-releases/news-release-details/harleydavidson-announces-fourth-quarter-full-year-2019-results 
Tabela 1: Crescimento e decrescimento de unidades vendidas

\begin{tabular}{|r|r|r|c|}
\hline País ou Região & \multicolumn{1}{|c|}{$\mathbf{2 0 1 8}$} & \multicolumn{1}{c|}{$\mathbf{2 0 1 9}$} & Mudança \\
\hline Estados Unidos & 132.868 & 125.960 & $-5,2 \%$ \\
\hline Canadá & 9.690 & 8.946 & $-7,7 \%$ \\
\hline Europa, Oriente Médio, África & 46.602 & 44.086 & $-5,4 \%$ \\
\hline Ásia, Oceania & 28.724 & 29.513 & $2,7 \%$ \\
\hline América Latina & 10.167 & 9.768 & $-3,9 \%$ \\
\hline Total & 228.051 & 218.273 & $-4,3 \%$ \\
\hline
\end{tabular}

Disponível em: http://investor.harley-davidson.com/news-releases/news-release-details/harleydavidson-announces-fourth-quarter-full-year-2019-results

O preço de uma moto zero quilômetros, saindo da concessionária, é a partir de $R \$ 53.300,00$, enquanto a mais cara sai a partir de $R \$ 199.500$, somando-se ainda o preço dos acessórios e produtos para a motocicleta, como alongamento do escapamento, tampa da gasolina modificada e diferentes assentos para a moto. Além dos produtos para o veículo, há outros produtos periféricos disponíveis para venda, como vestimentas, canecas, carteiras, chaveiros e relógios.

A Harley-Davidson organiza e patrocina uma comunidade da marca para aqueles que possuem suas motos, a Harley Owners Group (H.O.G). Ao adquirir uma das motos, o consumidor ganha automaticamente um ano de afiliação. Há também moto clubes devotos à marca que não são patrocinados pela empresa.

Desta forma, coloca-se a seguinte questão: por que consumidores devotos à marca Harley-Davidson participam de comunidades não oficiais de marca, quando a empresa já oferece uma comunidade oficial (a H.O.G)?

\subsection{Objetivo do estudo}

O objetivo desse estudo foi entender o porquê consumidores devotos à marca, participam de comunidades não oficiais de marca, quando a marca oferece uma comunidade oficial.

Como objetivos secundários, tem-se:

- Entender a relação dos consumidores com a marca Harley-Davidson;

- Investigar a relação desses consumidores com a comunidade de marca da qual participam. 


\subsection{Delimitações}

Este estudo volta-se especificamente para a questão de comunidades de marca sob o ponto de vista específico dos consumidores de Harley-Davidson no Rio de Janeiro. Não se pretende abordar o ponto de vista da empresa, nem de sua comunidade oficial de marca (H.O.G).

Embora relevante, não se pretende tratar da questão de retorno financeiro promovido pela relação dos consumidores com a empresa ou mesmo com as comunidades de marca.

\subsection{Relevância do estudo}

As informações que esse estudo pretendeu produzir podem se mostrar de interesse para as organizações, em especial a Harley-Davidson, posto que essa informação trata sobre seus consumidores, podendo se beneficiar futuramente com esses achados. Para outras organizações, os resultados podem contribuir para entender como avançar na construção de seu próprio valor de marca, inspirados no caso analisado.

Os resultados alcançados também poderão ser úteis para os consumidores, pois está falando diretamente sobre os comportamentos deles. Sob uma perspectiva filosófica, entender o comportamento, é entender a si mesmo. 


\section{Referencial Teórico}

Neste segundo capítulo são apresentados e discutidos aspectos conceituais e estudos relacionados ao tema e estudo em investigação e que servirão de base para a análise realizada.

Esta seção está dividida em três partes e abordam, respectivamente, a questão da identidade e consumo segundo Belk (1988), o conceito de brand equity segundo Keller e Machado (2006) e suas implicações para a construção do valor da marca. $\mathrm{Na}$ terceira seção discutem-se as perspectivas de Schouten e McAlexander (1995) sobre subcultura de consumo com foco na perspectiva de motociclistas inseridos em uma comunidade de marca.

\subsection{Identidade}

O que uma pessoa possui é entendido como parte dela, intencionalmente ou não, e é definido que a propriedade de uma pessoa é aquilo que ela pode chamar de seu (BELK, 1988). O que pode ser considerado o "eu" está dividido em oito categorias decrescentes do que é "seu" (PRELINGER,1959, apud BELK, 1988):

1. Partes do corpo (membros e órgãos);

2. Psicológico e intraorganismo (consciência);

3. Características de identificação pessoal e atributos (profissão);

4. Propriedades e produção (produtos);

5. Ideias abstratas (ética, moral, lei);

6. Outras pessoas (amigos, familiares, cidadãos da mesma cidade);

7. Objetos perto / tangíveis (móveis, terra);

8. Objetos longe / intangíveis (a lua, ou balcões de apenas funcionários).

Dentro do campo de estudos de identidade, há o conceito de representação, que ocorre quando um indivíduo é classificado dentro de algum grupo e seus observadores esperam ver neles sinais dessa classificação, de maneira implícita (GOFMANN, 2002). Por exemplo, espera-se que surfistas, emos, punks ou mesmo 
motociclistas tenham certo tipo de comportamento de acordo com a representação de sua categoria.

A roupa atualmente diz mais sobre a identidade social do que a identidade pessoal: a vestimenta é uma sinalização de gênero, classe social e status ocupacional. A maneira de se vestir é influenciada por diversas questões, como pressões de grupos, propaganda, recursos socioeconômicos e outros fatores que estimulam mais a padronização do que a diferença individual (GIDDENS, 2002). Ao entrar em um grupo, passam a seguir regras e rituais refletindo uma subcultura a qual o indivíduo se identifica.

\subsection{Brand Equity}

No século XX, com a necessidade de se determinar o valor de uma empresa, ocorreram, principalmente no mercado financeiro, abalos que precisavam de uma maneira de mensurar a compra de uma empresa e perceberam que os ativos intangíveis eram mais importantes que os tangíveis, pois sem conhecimento o maquinário fica improdutivo. Com os abalos que ocorreram aos ativos tangíveis das empresas, maquinários, na década de 1970, houve uma mudança na ênfase dos ativos, que então passou mais para os intangíveis, que são marcas, patentes, tecnologias, pesquisa, desenvolvimento e conhecimento. (DIAS; POSSAMAI, 2004); (DRUCKER 1998 apud ARAÚJO, 2007); (TEIXEIRA, 2010).

O conceito de brand equity surgiu por volta das décadas de 1970 e 1980 para auxiliar na determinação do valor da compra em processos de fusão e aquisição de grandes conglomerados. O brand equity é uma avaliação abstrata que os consumidores e/ou empresas fazem da marca (KELLER; MACHADO, 2006). Seu valor leva em conta o valor do produto ou serviço, somado ao conjunto de ativos e passivos ligados à marca (AAKER, 1998). Porém, apesar de estar relacionado a termos subjetivos, o brand equity normalmente lida com valor econômico de uma marca (BIEL, 1993).

Os passivos e ativos intangíveis de uma marca são (PINHO, 1996; AAKER, 1998; GOMES, 2015):

- Lealdade à marca: visto que o custo de conquistar novos clientes é bem elevado, manter os clientes se mostra vantajoso. Além disso, se a empresa mantiver o cliente satisfeito, diminui a ação de concorrentes; 
- Conhecimento do nome: "brand awareness" refere-se a se o consumidor lembra da marca. Sua importância deriva de que os consumidores geralmente escolhem as marcas que são mais familiares a eles. Em um esquema piramidal, na base ficaria o desconhecimento da marca, no estágio acima se reconhece a marca quando a vê, no penúltimo bloco se lembra da marca com outros tipos de reforços e no topo se a marca é a primeira que vêm à cabeça quando exposto a alguma categoria em que a marca está contida, conforme mostrado na Figura 2.

Figura 2: Pirâmide de conhecimento de marca

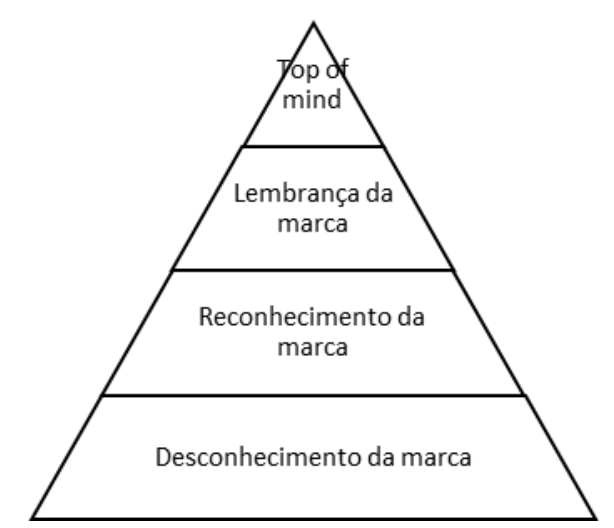

Fonte: Gomes, 2015 p.53

- Qualidade percebida: a percepção de qualidade influencia diretamente na decisão de compra do consumidor, permitindo a prática de preços premium e promove a marca para outros produtos;

- Associações à marca: a ligação que ocorre nas propagandas, o testemunho de personalidades ou características do produto. Exemplo:

- Apple: em situações que se fala da marca, ela é ligada a uma superioridade tecnológica, os consumidores têm uma percepção que os produtos estão avançados em relação as concorrentes;

- Tony Ramos e Friboi: a Friboi é considerada uma marca confiável porque Tony Ramos é o ator que anuncia as propagandas, e como os telespectadores confiam no ator, associam essa confiança com a marca. 
Outros ativos da marca: patentes, marcas registradas e relação com os canais de distribuição.

\subsubsection{Pirâmide de construção do Brand Equity}

A pirâmide de Brand Equity baseada no cliente (CBBE - customer based brand equity) foi desenvolvida por Keller e Machado ao partirem da premissa que o poder de uma marca está na mente dos clientes (GOMES, 2015). Para chegar no topo da pirâmide, ou seja, na ressonância, é necessário que a marca tenha sido construída por meio da sequência das etapas anteriores. A pirâmide de brand equity é mostrada na Figura 3, sendo cada um dos patamares explicado adiante.

Figura 3: Pirâmide CBBE (Keller e Machado, 2006 p.48)
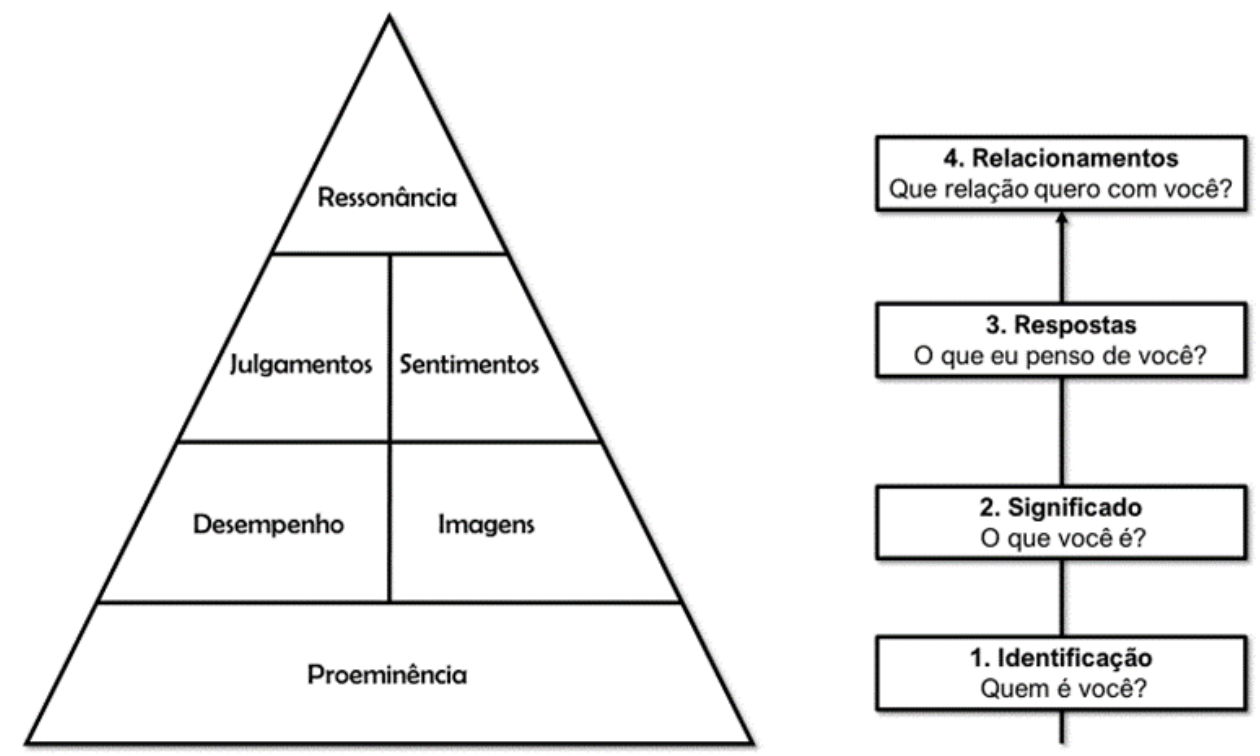

O primeiro patamar da pirâmide é composto por Proeminência que se refere à lembrança da marca, com que frequência e facilidade a marca é recordada em situações adversas. O nome, símbolo, slogan, logomarca devem estar ligados a associações na memória do cliente, não somente se estes ouviram falar ou já terem visto (KELLER; MACHADO, 2006).

O patamar seguinte na pirâmide de brand equity é formado por Desempenho e Imagens. O Desempenho da marca diz respeito a características intrínsecas do produto ou serviço, como seus componentes primários e características complementares; confiabilidade, durabilidade e disponibilidade do serviço; a 
efetividade, eficiência e empatia do serviço; o estilo e design; e o seu preço. As Imagens da marca, por sua vez, estão relacionadas às propriedades extrínsecas do produto ou serviço. Nesse bloco é como as pessoas pensam na marca abstratamente, podendo ser dividido em quatro ou mais categorias (KELLER; MACHADO, 2006):

1. Perfis de usuários: leva em consideração os fatores demográficos e psicográficos do usuário comum daquela marca;

2. Situações de compra e/ou consumo: condição que a marca deveria ser comprada e usada, se vai comprar em loja física ou online, se é o momento ou atividade certa para se usar o produto;

3. Personalidade e valores: marcas podem assumir traços de personalidade humana e contraindo princípios alinhados com os conceitos que os consumidores gostariam de ter de si mesmos;

4. História, legado e experiências: associações com eventos passados que a marca enfrentou.

O terceiro patamar da pirâmide de brand equity é composto por Julgamentos e Sentimentos. $\mathrm{Na}$ etapa de Julgamentos, estão envolvidas as associações de desempenho e imagem referindo-se às opiniões e avaliações dos clientes. Existem quatro tipos imediatos de julgamentos: sobre a qualidade (atributos e benefícios da marca); credibilidade (organização por trás do produto ou serviço, a marca podendo ser vista por exemplo como competente, inovadora, confiável, divertida, simpática, entre outros); consideração (se a marca consta das opções de compra do consumidor); e superioridade (percepção do cliente sobre a marca ser melhor que as outras e ser exclusiva) (KELLER; MACHADO, 2006).

Já os Sentimentos são as respostas e reações emocionais dos consumidores em relação à marca. As seis emoções destacadas por Keller e Machado (2006) são: ternura, diversão, entusiasmo, segurança, aprovação social e autoestima.

O último patamar da pirâmide foca no vínculo e o nível de identificação do cliente com a marca. Nesse patamar, há um vínculo psicológico entre consumidor e empresa, caracterizado pela profundidade ou intensidade. Há quatro subdivisões (KELLER; MACHADO, 2006): 
1. Fidelidade comportamental: a frequência com que o consumidor compra e o quanto gasta. É a repetição de compra naquela categoria e qual a porcentagem que a marca alcança nessas decisões de compra;

2. Ligação de atitude: é a conexão entre os consumidores e a marca, se as pessoas têm uma atitude positiva em relação a marca, aumenta a fidelidade, se tornam menos propensas a abandonar a marca pela concorrente;

3. Adesão ativa. Nessa etapa, o consumidor frente a outras marcas escolhe aquele que ele tem mais identificação de valor, a identificação é tão forte que o cliente vira um defensor da marca. Dependendo do grau de ressonância que a marca alcança, os consumidores criam grupos para compartilhar experiências e usufruir do estilo de vida que a marca carrega.

4. Senso de comunidade: o significado e a identificação com a marca são tão fortes que dão um senso de participação de uma comunidade. Nesse fenômeno social, os clientes sentem afinidades com outras pessoas associadas à marca, podendo ser os clientes, funcionários e representantes.

\subsection{Comunidade de marca}

Uma subcultura de consumo é um subgrupo distinto da sociedade, com uma estrutura hierárquica, conjunto de crenças e valores, jargões, rituais e símbolos únicos, que se baseia em um compromisso compartilhado com uma determinada classe de produto, marca ou atividade de consumo (SHOUTEN; MCALEXANDER, 1995). Uma comunidade de marca é constituída pelos seus membros e pelo relacionamento entre eles. São reconhecidas pela semelhança ou identificação entre os membros, podendo ser de um bairro, uma atividade de lazer ou a devoção a uma marca (MCALEXANDER ET AL, 2002). Uma comunidade de marca é uma comunidade especializada sem necessariamente estar geograficamente ligada, baseado em um conjunto de estruturas e relações sociais entre admiradores de uma marca (MUNIZ; O'GUINN, 2001).

Três características identificam as comunidades de marca (KOTLER; KELLER 2012): 
1. Um senso de conexão com a marca, empresa, produto ou outros membros da comunidade;

2. Rituais, histórias e tradições compartilhadas que ajudam a transmitir o significado da comunidade;

3. Uma responsabilidade ou um dever moral entre todos os participantes juntos e individualmente.

Alcançar uma comunidade de marca forte tem como resultado clientes fiéis e comprometidos, capazes de defender, dar feedback para melhorias ou inspiração para inovações. O suporte desses defensores pode chegar a substituir atividades que a empresa teria que alocar recursos, gerando uma maior eficiência e eficácia de marketing (KOTLER; KELLER, 2012). Apesar de sempre ser retratado na área de marketing, a comunidade de marca é estratégia do negócio (FOURNIER; LEE, 2009).

Ao estar inserido em uma comunidade de marca, o usuário está dentro de uma nova cultura, seguindo novas regras e rituais, o que é classificado como uma subcultura. Essa subcultura pode ser classificada como um subgrupo da sociedade. Essa relação é mostrada na Figura 4. 
Figura 4: Diagrama sociedade

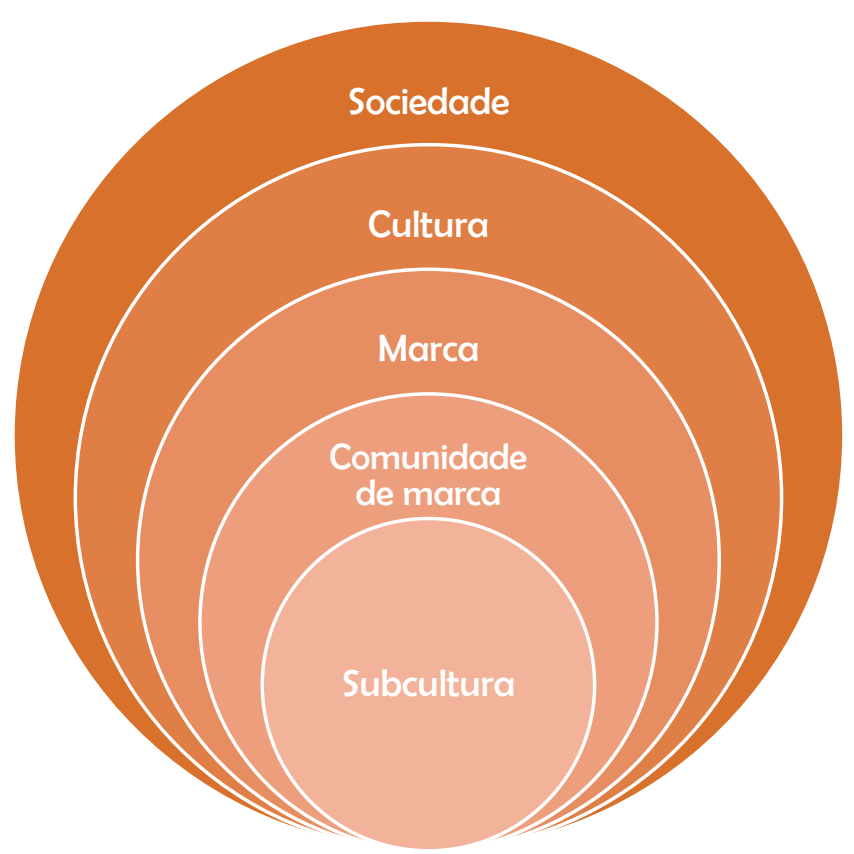

\subsubsection{Comunidade de Marca da Harley-Davidson}

Um dos casos de comunidade de marca foi estudado por Schouten e McAlexander (1995), baseada em consumidores da Harley-Davidson, em que retratam a subcultura do consumo dos "new bikers" de uma perspectiva etnográfica. Como conclusão do estudo, os autores desenvolveram um referencial teórico sobre subculturas voltadas para o consumo. A subcultura está presente em todo tipo de atividade e que essas atividades influenciam na maneira que o indivíduo irá comprar, se comportar e absorver informações da mídia e de conteúdo, unindo um grupo de pessoas que terão valores e comportamento de consumos iguais.

Nessa cultura de consumo, não é levado em conta a construção social do indivíduo e sim as atividades, objetos e relações que dão sentido à vida. São com esses objetos, possessões, que 0 indivíduo consegue se inserir socialmente no mundo, se relacionando com outras pessoas, compartilhando os mesmos valores e interesses (SCHOUTEN; MCALEXANDER, 1995).

O estudo também percebeu que dentro dessas subculturas há uma questão hierárquica baseada em comprometimento com os padrões de consumo que 0 indivíduo tem na ideologia da subcultura. $E$ que os rituais facilitam $O$ compartilhamento e o reforço do significado daquele grupo (SCHOUTEN; MCALEXANDER, 1995). 


\section{Metodologia}

Esse capítulo busca explicar como ocorreu a pesquisa, qual era o universo da pesquisa, qual o método utilizado e como foi feita a coleta e tratamento de dados e quais as limitações que esse método causa na pesquisa.

\subsection{Método de Pesquisa}

A pesquisa foi realizada por meio de entrevistas qualitativas seguindo um roteiro semiestruturado, sem a preocupação com a representatividade numérica e sim com o aprofundamento da compreensão de fenômenos (GERHARDT; SILVEIRA 2009). A escolha desse método se deu pelo caráter investigativo do trabalho e para entender características mais complexas e não quantificáveis como sentimentos e comportamentos em relação a marca Harley-Davidson.

\subsection{Universo da pesquisa}

A realização da presente pesquisa foi feita com 15 integrantes de comunidades não oficiais à Harley-Davidson para que fosse possível entender o porquê consumidores devotos à marca, participam de comunidades não oficiais de marca, quando a marca oferece uma comunidade oficial.

O grupo de respondentes foi definido através da técnica metodológica da bola de neve, um método de amostra não probabilística útil para selecionar participantes na pesquisa em grupos difíceis de serem acessados (BERNARD 2005, apud VINUTO 2014). Essa ferramenta aproveita a rede de contato do participante para ter participantes na pesquisa de modo permanente e encerrado quando as respostas atingem um ponto de saturação e repetição (VINUTO, 2014). 


\subsection{Coleta e tratamento de dados}

A coleta de dados escolhida foi a distância para evitar um contato pessoal entre pesquisador e entrevistados, uma vez que ocorreram durante a pandemia do Covid19 e alguns eram do grupo de risco.

O primeiro contato era feito por mensagem de texto, a fim de apresentar o propósito do trabalho e o pesquisador do trabalho. Após uma introdução, era marcado um horário específico e realizadas por ligação ou por chamada de vídeo se o entrevistado se sentisse mais confortável.

A segunda etapa consistia na entrevista, começando por perguntas gerais com o intuito do entrevistado ficar mais confortável e ter confiança que os dados pessoais não seriam expostos. Posteriormente era pedido que o participante contasse um pouco mais da relação dele com a marca e com a comunidade que estava inserido. Um roteiro semiestruturado foi utilizado, e perguntas como: O que a marca HarleyDavidson significa para você? O que Ihe levou a se tornar membro da comunidade que você está? O que fazer parte de uma comunidade diz a respeito de você? $\mathrm{E}$ outras perguntas complementares que se encaixavam na conversa também foram utilizadas. O roteiro de entrevistas se encontra no Anexo 1.

O tratamento de dados foi feito através da transcrição parcial das entrevistas em um arquivo de texto para que as falas testemunho dos entrevistados dessem suporte a análise feita pelo autor visto que as conversas não poderiam ser gravadas devido a informações particulares do grupo.

\subsection{Limitações do estudo}

O método de busca de entrevistados por indicação (bola de neve) é eficaz para populações relativamente pequenas, o que traz limitações para o estudo, como um provável viés de respostas muito semelhantes, visto que os entrevistados indicam pessoas de sua rede pessoal (VINUTO, 2014).

Outro problema é que o pesquisador herda as decisões de seleção de entrevistados por quem os indica, podendo levar o pesquisador a coletar dados que refletem perspectivas já ditas, omitindo opiniões de outros que não fazem parte da 
rede (MAY, 2004, apud VINUTO 2014), resultando em viés na seleção de informantes, em que alguns indivíduos tem mais chance de serem selecionados.

O viés da confirmação também tende a ser um problema para o lado do entrevistador que tenta confirmar as impressões prévias após a execução das entrevistas (ARAÚJO; PILATI, 2014). 


\section{Análise dos Resultados}

A pesquisa teve como objetivo entender por que consumidores devotos à marca Harley-Davidson participam de comunidades não oficiais, uma vez que a marca patrocina uma comunidade oficial, a H.O.G. Para tanto, foram feitas 15 entrevistas com membros de doze comunidades não oficiais diferentes, e alguns dos entrevistados participam ou já participaram da H.O.G como mostrado no quadro a seguir:

Figura 5: Identificação dos entrevistados

\begin{tabular}{|c|c|c|c|c|}
\hline Identificação & Gênero & Idade & Comunidade & HOG \\
\hline E1 & Homem & 23 & C1 & Não \\
\hline E2 & Homem & 46 & C1 & Não \\
\hline E3 & Homem & 46 & C2 & Não \\
\hline E4 & Homem & 49 & C3 & Sim \\
\hline E5 & Homem & 61 & C4 & Não \\
\hline E6 & Homem & 45 & C4 & Sim \\
\hline E7 & Homem & 50 & C5 & Não \\
\hline E8 & Homem & 54 & C6 & Sim \\
\hline E9 & Homem & 27 & C7 & Não \\
\hline E10 & Homem & 56 & C8 & Sim \\
\hline E11 & Homem & 52 & C9 & Sim \\
\hline E12 & Homem & 53 & C10 & Sim \\
\hline E13 & Mulher & 37 & C11 & Não \\
\hline E14 & Mulher & 34 & C11 & Não \\
\hline E15 & Mulher & 52 & C12 & Sim \\
\hline
\end{tabular}

Vale salientar que a falta de mais respondentes do sexo feminino vem de encontro com o machismo presente nesse meio do motociclismo. "A comunidade representa mais essa galera mais velha, machista, nesse grupo só entra homem" (E1); "É um mundo machista" (E10); "Nunca quis fazer parte de moto clube masculino por ser um meio extremamente machista, e fazer parte de um coletivo feminino da uma força" (E13); "Sim, meio do motociclismo é muito machista, não me sinto confortável andando com homens" (E14). Ao mesmo tempo, as entrevistas com três mulheres pertencentes a essas comunidades permitem um olhar mais 
abrangente de possíveis questões de gênero, apesar de não terem sido parte dos objetivos intermediários planejados para o estudo.

\subsection{A Marca Harley-Davidson}

O produto "motocicleta Harley-Davidson" e a marca se confundem e são geralmente tratados como inseparáveis pelos entrevistados. O sentimento em relação entre os entrevistados e a marca - ou o que o produto promove - é de liberdade, tranquilidade e até de autoridade, retratado por exemplo nas falas a seguir: "Você subir numa Harley e pegar a estrada é como se você pudesse acertar toda a sua vida naquele momento" (E4); "Harley-Davidson é liberdade, vento na cara, aquele barulho lindo" (E8); "A Harley-Davidson pra mim é uma lenda, tem uma história por trás" (E9); "A Harley meio que me enfeitiçou, é muito deslumbrante, toda uma história, uma lenda" (E13); "Ter uma Harley-Davidson te causa um empoderamento muito forte, te dá uma sensação de liberdade" (E15).

Os entrevistados traziam como resposta a sensação de liberdade, o vento na cara e o barulho característico do moto como sendo únicos da Harley-Davidson, os fazendo escolher essa moto ao invés das concorrentes.

Para os consumidores, a marca está bastante presente na memória. Não à toa, muitos deles tatuam no corpo a logomarca da Harley-Davidson, a moto ou a águia que a representa. "A Harley-Davidson é a única marca registrada no mundo que o ser humano tatua no corpo" (E6). Quatro dos entrevistados declararam ter tatuagens relacionados à marca e dois outros disseram que pensam em fazê-lo.

Os próprios usuários se veem com o perfil e personalidade muito ligadas a filmes de Hollywood: "Sonhava em ter uma Harley-Davidson, a gente via em filme americano" (E5); "Me identificava muito quando via aqueles filmes americanos, com motos grandes, moto clubes" (E6); "Minha relação com a marca é que é um sonho de infância e Hollywood tem a ver com isso, o Exterminador em uma Fat Boy me fez querer uma Fat Boy e Harley era uma moto que aparecia muito em filme" (E11).

Os respondentes têm grande consideração à marca e a colocam como prioridade nas opções de compra, conectado com o terceiro patamar da pirâmide de brand equity como Julgamento de consideração: "É um ícone, a marca pesou perante as outras" (E8); "Já amava a marca, opção sempre foi Harley e não as concorrentes" (E13); "Comprei a Harley pensando unicamente em Harley” (E14). 
Os entrevistados enxergam como superior e exclusiva, porque ela é fortemente ligada ao tipo de modelo e o preço dela, refletindo na confiança, durabilidade e serviço prestado, também ligado ao terceiro patamar da pirâmide de brand equity de Keller e Machado (2006) em Sentimento: "Eu acho que é o poder da marca, de você estar numa Harley-Davidson, a palavra é poder, ter uma Harley é ter status" (E13); "Quando você senta em uma Harley-Davidson, você é tratado diferente, com educação e respeito, as pessoas te acham irada" (E14).

Além disso, alguns entrevistados comentaram que é uma moto pouco roubada no Rio de Janeiro por ser mais pesada e diferente de pilotagem e não serem feitas para subir morros, além dos usuários incentivarem a compra de peças apenas com procedência verificada. Dados os índices de criminalidade na cidade do Rio de Janeiro, esse fator dá um peso adicional à escolha da moto. Isso pesou na escolha dos entrevistados: "É uma moto pouco roubada, então o seguro é mais barato, só para ter uma noção na minha outra moto o seguro é de cinco mil reais, enquanto na minha Harley zero é mil e oitocentos" (E5); "Escolhi a Harley por ser pouco roubada, a minha outra opção era a mais roubada, aí pesou" (E15).

Em suma, é entendido que a marca traz aos seus consumidores sentimentos de segurança, por ser uma moto pouco roubada; aprovação social, visto que a maneira como as outras pessoas enxergam é positiva; e autoestima, porque faz com que os consumidores se sintam melhores consigo mesmos.

Os entrevistados se identificam muito com a marca, sendo fiéis a ela e sem chance de mudar para alguma concorrente, pois depois que experimentaram a "sensação de vento na cara" da Harley decidiram não trocar mais, visto que nenhuma outra dava esse benefício, "As outras motos são gostosas, mas eu sou Harley-Davidson" (E10).

O hábito de consumo também está relacionado com o motociclismo e principalmente com Harley-Davidson. Todos os entrevistados compram periféricos para as motos e outros produtos de vestimenta, principalmente a jaqueta de couro da marca, em coerência com Belk (1988) que o que uma pessoa possui é entendido como parte dela: "Tenho tudo da Harley, mais de 20 jaquetas, mais de quatro botas, mais de 50 camisas e sempre que eu subo na minha Harley tenho que estar com alguma coisa de Harley" (E4); "Tenho tudo da Harley: jaqueta, camisa, botina e uso porque gosto da marca e a lenda, todo o marketing que tem em cima" (E10); "Tenho um closet inteiro da Harley com botas, camisas, bolsas, meias, luva, jaqueta, calça, 
pijama, anel e tenho um espaço Harley na casa, relógio, bar e todo dia vou estar com alguma peça da Harley" (E15). O caso mais emblemático foi o do E8 que só viaja para algum lugar se tiver uma loja Harley-Davidson para poder comprar uma camisa: "Tenho a maior coleção de camisas de Harley do Rio, com mais de 300 camisas, e só usa camisa da Harley, menos no trabalho" e "Só viajo pro exterior pra um local que tenha loja Harley-Davidson, porque eu não viajo pra conhecer o lugar, não; eu viajo pra conhecer a loja".

\subsection{Comunidade de Marca Harley-Davidson - H.O.G.}

A H.O.G. é a comunidade oficial da marca e sua organização e eventos fica a critério de cada concessionária Harley-Davidson. No entanto, a concessionária do bairro do Recreio dos Bandeirantes promove semanalmente, aos sábados, o "café da manhã da Harley", sendo oferecido um lanche e um briefing com informações e regras para o passeio do dia, que geralmente é um bate-volta (ir e voltar no mesmo dia) curto com o intuito de fidelizar o cliente. "O que eu vejo da H.O.G. é uma ideia legal da empresa de fidelizar" (E11).

Um dos achados dessa pesquisa é que, conforme relatado pelos entrevistados, alguns consumidores da marca não queriam participar da H.O.G. e decidiram abrir suas próprias comunidades de marca, por terem alguma aversão a H.O.G.'s. Esse parece ter sido um dos motivadores à criação de diferentes comunidades não oficiais.

Para os entrevistados, os assinantes da HOG são "coxinhas" e fake bikers, definidos como: "Qualquer pessoa que tenha dinheiro, compra uma Harley e vai usar somente no final de semana" (E4). Para o E1, que é mais jovem, são "Coroas com pensamento muito diferente do meu. Muito reacionária, militarista". Afinal, "Moto [Harley-Davidson] você pilota" (E3), não usa somente para um passeio no final de semana e sim para subir na moto e fazer viagens e rodar vários quilômetros com ela e não levar "cinco anos para rodar mil quilômetros com a moto" (E1), e nem ser um "RPM", definido pelo E11 como "Roda Pelo Município".

Com essa visão que a H.O.G. só anda no final de semana e para passeios curtos, eles são considerados inexperientes e, ao andar na formação, colocam as outras pessoas em risco: "Na H.O.G. é gente sem experiência e acontece muito acidente" (E6); "Não tinha vontade de andar com os caras, muita gente sem 
experiência e sem segurança" (E4); "Tenho pânico do trem da H.O.G. porque tive uma péssima experiência por serem irresponsáveis" (E13); "Pessoas de níveis diferentes, muita gente diferente, porque a H.O.G. não se importa” (E15).

Para os entrevistados há uma necessidade de ter alta quilometragem na moto, porque isso diferencia os verdadeiros motociclistas dos fake bikers, por isso os respondentes recomendaram perguntar a quilometragem com 0 intuito das informações fornecidas tenham veracidade.

E, apesar do ritual de o comprador tocar o sino quando compra uma Harley zero quilômetros na concessionária e todos que estão na loja aplaudirem, e até mesmo de poderem iniciar um papo e apresentar a H.O.G., para os entrevistados essa comunidade não tem o mesmo senso de irmandade que encontram nas comunidades não oficiais da marca.

\subsection{Comunidades Não Oficiais de Marca}

Conforme relatam os entrevistados, há diversas comunidades não oficiais da marca Harley-Davidson, entre moto clubes, moto grupos e coletivos. Moto clube é uma associação com CNPJ, com direitos e deveres do participante registrados em um estatuto, geralmente com um código de conduta e vestimenta requerida. $\mathrm{O}$ moto grupo é mais informal que o moto clube, mas ainda há deveres que o participante deve cumprir. Já no coletivo não há regras formais e é mais abrangente.

No aspecto de subcultura dessas comunidades, os entrevistados relataram que nas mais tradicionais há todo um regramento interno com normas e práticas que devem ser seguidas. A hierarquia é muito presente, com a imagem de um presidente, vice-presidente, escudos, meio escudos, prósperos e "hang outs", além da existência de uma tesouraria e uma assembleia.

Os entrevistados explicam que, para se entrar em um moto clube mais tradicional, um indivíduo começa a rodar com o clube, sendo considerado um hang out. Nessa etapa, o clube e o motociclista vão se conhecendo para ver se as filosofias se conectam. O hang out passa dois meses rodando com o grupo e conhecendo o clube, mas sem fazer parte dele. Após esse período de experimentação, ele pode ser convidado e indicado por alguém de dentro do clube, tornando-se um próspero pretendente (PP) (também chamado de suporte ou aspirante) e recebe um padrinho, começando a pagar uma mensalidade. Após um 
período de seis meses, se o padrinho achar que ele está pronto, leva a questão a uma assembleia, que debate se o candidato será promovido ou não. Para ser aprovado, tem que ter a concordância da maioria dos membros da assembleia. Caso seja aprovado, recebe o primeiro patch com uma parte da escuderia para colocar no colete na parte da frente e tem que ficar no mínimo um ano nessa etapa até ser indicado pelo padrinho novamente. Com a possibilidade de ser indicado, a votação na assembleia tem que ser unânime e, caso seja aprovado, ganha um escudo de metal com a marca no peito e uma escuderia atrás na jaqueta.

As partes mais abaixo da hierarquia têm que mostrar dedicação, servindo, lavando e cuidando das motos, para que os escudados, como são chamados os de patente mais alta, possam ficar mais livres para aproveitar seus momentos no grupo. Isso é uma prática reforçada pelos grupos tradicionais, pois todos os membros de patente mais elevada passaram por isso.

Em alguns clubes há um código de vestimenta, como só poder andar de calça jeans, camisa preta e bota, mas na maior parte dos casos não há um código, apenas uma padronização no colete. Isso ocorre não somente nos moto clubes tradicionais, mas também nos moto grupos e coletivos, que têm um código de vestimenta, mesmo que somente para eventos de grande porte. Giddens (2002) evidencia que a maneira de se vestir é influenciada por pressões do grupo, estimulando mais a padronização e que ao entrarem em um grupo, se inserem em uma subcultura e passam a seguir regras e rituais as quais se identificam, muito alinhado também com a definição de subcultura de Schouten e McAlexander (1995).

Independente da categoria da comunidade, a maioria cobra uma mensalidade ou anuidade, que varia de $\mathrm{R} \$ 30,00$ a $\mathrm{R} \$ 220,00$ dependendo do tamanho do grupo. Os entrevistados, apesar de ser uma informação de interesse apenas do grupo, sentiam-se confortáveis em compartilhar algumas informações, mas para informações que tinham que passar pela assembleia eram confidenciais ao entrevistador, como por exemplo o número de afiliados do clube ou qual seria a próxima viagem.

Todas as comunidades têm encontros semanais, em alguns há a necessidade de ter um "bate-volta" uma vez na semana e um "bate e fica" (envolvendo ao menos um pernoite) com uma certa periodicidade. A falta de presença de algum membro é mal vista pelos outros, e aquele perde credibilidade perante o grupo. 
Os entrevistados sentem que fazem parte de uma família com uma filosofia de vida similar uns com os outros, evidenciando o achado de Prelinger (1959) de que outras pessoas influenciam quem somos. "O moto clube faz parte de quem sou hoje, estou sempre com o colete do moto clube" (E5); "A vida inteira eu me importei com o outro independente de quem seja, ajudar o próximo e isso tem muito a ver com o espírito de moto clube" (E6); "No motociclismo não existe diferença se você é rico, pobre" (E9); "Tem tudo a ver eu sou meu moto clube, sou irmão dos caras e os caras são meus irmãos" (E10); "Agregar pessoas que tenham a mesma filosofia de vida, felicidade, falar de viagens, trocar valores culturais a estar associado a você estar de moto" (E15).

Assim, é parte da motivação para se buscar uma comunidade não oficial da marca a busca por uma identificação e fazer parte de uma família, visto que para alguns o moto clube vem em primeiro lugar e a marca está ali apenas para apoiar: "Não boto nada da Harley não, só uso do meu clube porque clube acima da marca" (E7); "Não sou tão fissurado pela marca, mas sempre estou com o colete do meu moto clube" (E9). Inclusive, a tatuagem que E6 fez nas costas foi do emblema do moto clube - não da marca Harley-Davidson em si.

O senso de conexão, rituais compartilhados entre os membros e o dever moral entre os participantes expostos nesse capítulo estão relacionados diretamente com a definição de Keller e Machado (2006) sobre a identificação de uma comunidade de marca. 


\section{Conclusão}

Este capítulo resume as principais contribuições produzidas ao tema em estudo. O ângulo de análise proposto se mostrou relevante porque são poucas marcas que chegam ao patamar de ressonância, em que seus clientes viram leais a marca, assim como acontece com a Harley-Davidson.

Esse trabalho pretendeu investigar o porquê de consumidores devotos à marca Harley-Davidson participarem de comunidades não oficiais de marca, enquanto a empresa oferece uma comunidade oficial. $O$ foco do estudo recaiu sobre moto clubes, moto grupos e coletivos monomarca Harley-Davidson e tal questão se mostra importante à medida que pode contribuir a outras organizações como entender e avançar na construção de seu próprio valor de marca.

Para aprofundar a análise pretendida investigou-se a perspectiva de Belk (1988) quanto ao "eu", a de Schouten e McAlexander (1995) quanto à subcultura de consumo da comunidade de motociclistas Harley-Davidson e a de Keller e Machado (2006) quanto a identificação de comunidades de marca.

Para atingir os objetivos pretendidos realizou-se a pesquisa de campo. Foram realizadas 15 entrevistas com membros de doze comunidades não oficiais de marca distintas.

Conclui-se que a Harley-Davidson faz um trabalho com a H.O.G que insere os interessados nesse mundo do motociclismo, mas ao ganhar experiência o cliente prefere migrar para clubes mais focados a fim de evitar os mais inexperientes e os riscos.

Apesar dos entrevistados terem uma visão positiva e entenderem toda a construção de marca que a empresa faz, o modo de vida que a empresa vende não se espelha na H.O.G. por isso os respondentes vão para comunidades que tenham a filosofia e estilo de vida que a marca reforça. Então cabe a Harley-Davidson fazer com que a H.O.G. se aprofunde mais no estilo que a marca deseja, com viagens maiores e uma hierarquia mais definida. 
Outras organizações podem se beneficiar com esses achados, de como aplicar a pirâmide de brand equity e construir uma marca mais forte, além de conseguirem estudar a criação de uma comunidade de marca ativa.

Como desdobramentos futuros, essa linha de estudo pode ser desenvolvida através de investigação sobre a inserção de mulheres nesse meio tão masculino, visto que estas estão crescendo cada vez mais nesse meio e a entrada do ambiente familiar nessas comunidades como cônjuge e filhos. 


\section{Referências}

AAKER, David A. Marcas: Brand Equity - gerenciando o valor da marca; tradução André Andrade. São Paulo: Negócio Editora, 1998.

ARAÚJO, Maria E. B. O.; PILATI, Ronaldo. Viés de confirmação em entrevista de seleção: evidências em estudantes universitários. Revista Psicologia: Organizações e Trabalho, Brasília, v. 14, n. 1, p. 67-77, 2014.

BALDAUF, A.; CRAVENS, K. S.; BINDER, G. Performance consequences of brand equity management: evidence from organizations in the value chain. Journal of Product $\&$ Brand Manangement, v.12, n.4, p.220-236, 2003.

BELK, Russell W. (1988), "Possessions and the Extended Self," Journal of Consumer Research, 2(September), 139-68.

DIAS Jr., C. M.; POSSAMAI, O. A importância dos ativos intangíveis na concepção de organizações orientadas pelo conhecimento. Rev. FAE, v. 7, n. 2, p.3-8, jul./dez. 2004. FOURNIER, Susan.; LEE, Lara. Getting brand communities right. Harvard Business Review, p. $105-11$, abr 2009.

GOMES, Mauricio de Brito. Gestão de produtos e marcas. Editora FGV, 2015.

GERHARDT, T. E.; SILVEIRA, D. T. Métodos de Pesquisa. Série Educação a Distância. Coordenado pela Universidade Aberta do Brasil - UAB/UFRGS e pelo Curso de Graduação Tecnológica - Planejamento e Gestão para o Desenvolvimento Rural da SEAD/UFRGS.

GIDDENS, Anthony. Modernidade e identidade. Rio de Janeiro: Jorge Zahar, 2002.

GOFFMAN, E. (2002). A representação do eu na vida cotidiana; tradução: Maria Célia Santos Raposo. Petrópolis: Vozes

HAWKINS, Del I.; MOTHERSBAUGH, David L. Comportamento do Consumidor: construindo a estratégia de marketing; tradução Paula Santos Diniz - 13 ed. - Rio de Janeiro: Elsevier, 2019

KELLER, Kevin Lane. MACHADO, Marcos. Gestão estratégica de marcas. São Paulo: Person Prentice Hall, 2006. 
LEÃO, A. L. M. de S.; IANATONI, T.; CAVALCANTI, R. T. Identidades Culturais de Consumidores da Pitú em sua Comunidade de Marca: Uma Netnografia da Comunicação. Revista de Gestão Organizacional, v. 8, n. 2, p. 60-81, 2015.

MCALEXANDER, James H., SCHOUTEN, John W., KOENIG, Harold F. (2002), "Building Brand Community," Journal of Marketing, 66 (January), 38-54.

MUNIZ, A. M. JR.; O'GUINN, T. C. Brand community. Journal of Consumer Research, v. 27, p. 412-432, 2001.

OLIVEIRA, M. O. R.; LUCE, F. B. O valor da marca: conceitos, abordagens e estudos no Brasil. REAd. Revista Eletrônica de Administração, v. 17, n. 2, p. 502-529, 2011.

PINHO, José Benedito. O poder das marcas. São Paulo: Summus, 1996

SCHOUTEN, John; MCALEXANDER, James H. (1995), "Subcultures of Consumption: An Ethnography of the New Bikers," Journal of Consumer Research, 22 (June), 43-61

TEIXEIRA, J. P.; PETRI, S. M.; MARQUES, T. O. O valor da marca como um ativo intangível: um estudo de caso da WEG SA. Revista de Contabilidade do Mestrado em Ciências Contábeis da UERJ, v. 17, n. 2, p. 45-67, 2012

VERGARA, Sylvia Constant. Projetos e relatórios de pesquisa em administração. São Paulo: Atlas, 1997.

VINUTO, J. A amostragem de bola de neve em pesquisa qualitativa: um debate aberto. Temáticas, Campinas, v. 22, n. 44, p. 203-220, 2014.

COATS, Jenni; BURNS, Shannon. Harley-Davidson Announces Fourth Quarter, Full-Year 2019 Results. Milwaukee, 28 jan. 2020. Disponível em: http://investor.harleydavidson.com/news-releases/news-release-details/harley-davidson-announces-fourthquarter-full-year-2019-results. Acesso em: 6 set. 2020.

DE ARAÚJO, Geraldino Carneiro. O capital intelectual dentro do ativo intangível. [S. I.], 2007. Disponível em: https://classecontabil.com.br/o-capital-intelectual-dentro-do-ativointangivel/. Acesso em: 2 ago. 2020

TEXEIRA, William. Harley-Davidson cresce no Brasil pelo terceiro ano seguido. [S. I.], 6 fev. 2020. Disponível em: https://www.motociclismoonline.com.br/noticias/harley-davidsoncresce-brasil-2019/. Acesso em: 3 ago. 2020. 
Anexo

Roteiro

Nome:

Idade:

Sexo:

Bairro onde mora:

Comunidade:

Bairro da sede:

Patente:

Modelo:

Tempo de moto:

Tempo de clube:

$\mathrm{KM}$ rodados:

Mensalidade:

Qual a sua relação com a marca? Conta a sua história.

O que a marca Harley significa para você?

Por que escolheu a Harley?

Você já participou do HOG? Por quê? (Se sim, como foi a experiência? Por que saiu?) Como você vê a HOG? E os motoqueiros que participam dele?

Faz parte de uma comunidade paralela? Por quê?

O que lhe levou a se tornar membro do moto clube em que você está?

O que "fazer parte do moto clube" diz a respeito de você? (o que o moto clube tem a ver com você?)

O que você gosta nele? E o que não gosta?

Como é a sua rotina com a sua Harley-Davidson? (explorar não apenas o uso da moto, como também a relação com o moto clube)

Como você se enxerga em relação a esse moto clube daqui a uns 10, 15 anos? $\mathrm{E}$ daqui a 20 ou mais?

Como é a cultura do grupo?

Tem outros produtos Harley-Davidson? 